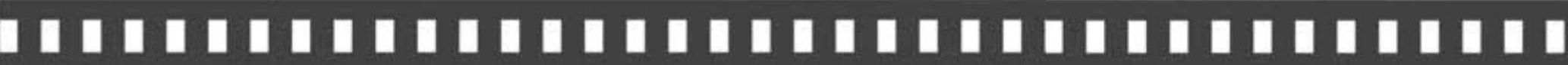

\section{Fotolivro: cotidiano e tradições da comunidade Jaçatuba}

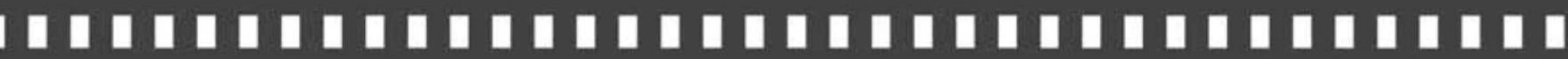

Marcus Elicius dos Santos Garcez

Mary Aurea de Almeida Costa Everton

Silvio Rogério Rocha de Castro

Artigo recebido em: 08/08/2019

Artigo aprovado em: 08/06/2020 


\title{
Fotolivro: cotidiano e tradições da comunidade Juçatuba
}

\author{
Photobook: daily life and traditions of the Juçatuba community
}

\author{
Marcus Elicius dos Santos Garcez* \\ Mary Aurea de Almeida Costa Everton** \\ Silvio Rogério Rocha de Castro ${ }^{* * * *}$
}

\begin{abstract}
Resumo: Este trabalho tem por objetivo refletir sobre as imagens fotográficas como fonte de informação e memória, através do fotolivro "Juçatuba: cotidiano e tradições". Para tanto, traz análises ao longo do artigo sobre a importância deste trabalho para a comunicação e, ainda, as etapas de construção do fotolivro. A metodologia envolve pesquisa exploratória e participante, com observações em campo, realizações de ensaios fotográficos, entrevistas semiestruturadas, além de pesquisas bibliográficas e documental.
\end{abstract}

Palavras-chave: Comunicação. Fotografia documental. Memória. Fotolivro. Juçatuba.

Abstract: This work aims to reflect on photographic images as a source of information and memory, through the photobook

* Fotógrafo. Mestrando pelo Programa de Pós-Graduação em Comunicação e Sociedade, da Universidade Federal do Tocantins. Graduado em Comunicação Social - Rádio e TV, pela Universidade Federal do Maranhão (2018), E-mail: eliciusmarcus@gmail.com.

** Fotógrafa profissional de carreira autoral (1994). Graduou-se em Comunicação Social Habilitação Publicidade e Propaganda - Universidade UniCeuma (2001). Mestranda no Programa de Pós-Graduação em Comunicação - Mestrado Profissional linha de Pesquisa: LP1. Comunicação Institucional e Mercadológica - UFMA. E-mail: labfotografiaufma@gmail.com

*** Doutor em Ciências da Comunicação pela Universidade de São Paulo (2004). Professor associado do curso de Comunicação Social, da Universidade Federal do Maranhão. E-mail: silvioroger@uol.com.br 
"Juçatuba: daily life and traditions". Therefore, it brings analyses throughout the article about the importance of this work for the Communication field as well as the stages of construction of the photobook. The methodology involves exploratory and participant research, with field observations, photographic essays, semi-structured interviews, as well as bibliographic and documentary research.

Keywords: Communication. Documentary photography. Memory. Photobook. Juçatuba.

\section{Introdução}

A comunicação tem um papel importante na compreensão dos processos que envolvem a relação do homem com outra pessoa e do homem com um objeto, de forma a analisar as transformações nas tradições ao longo do tempo. Analisa, ainda, as mudanças que ocorrem no cotidiano com a inserção de tecnologias digitais de informação, ou mesmo de meios técnicos, como geladeiras, televisões e serviços de transporte. Além disso, a comunicação tem um papel fundamental na reflexão do cotidiano, devido ao presente indicar também situações do passado, a partir do entrelaçamento deles, como coloca Barbosa (2009).

O uso da imagem fotográfica então, como fonte de informação, é essencial para essa reflexão sobre o cotidiano, tendo em vista que registra um fragmento da realidade, guardando para a posteridade modos de vida de um dado momento da história. Como afirma Kossoy (2009), a fotografia se estabelece em nós como um arquivo de referência para o conhecimento do mundo, de modo a estar em constante movimento, mesclando-se ao que somos, pensamos e fazemos. 
Dessa forma, busco neste trabalho refletir sobre a imagem fotográfica como fonte de informação e local de memória, através do fotolivro "Juçatuba: cotidiano e tradições". Essa reflexão envolve uma discussão teórica com autores, como Kossoy (2012), Andrade (2002) e Barbosa (2016). Também busco discutir a importância deste trabalho para o campo da comunicação e relato as etapas de construção do fotolivro.

Diante de diversas comunidades para serem trabalhadas, foi escolhida Juçatuba, por ser uma das poucas do município de São José de Ribamar/MA a ter o reconhecimento como remanescente de quilombos, através da Fundação Cultural Palmares ${ }^{1}$, desde 2007.

Juçatuba é um povoado localizado na zona rural do município, Região Metropolitana de São Luís/MA. Sua história é imprecisa, sendo disponível apenas através de relatos de moradores. Segundo eles, sua origem é de descendência de escravos fugidos de sobrenome Garcês. Mesmo localizada na zona rural, a comunidade já apresenta reflexos de uma infraestrutura urbana, com água encanada, energia elétrica, telefone, transporte público, escolas, posto de saúde e coleta de lixo. Juçatuba ainda realiza festejos religiosos e culturais, como o Tambor de Mina e Bumba-Meu-Boi. Porém, segundo relatos de pessoas mais antigas do local, obtidos por meio de pesquisa exploratória no local, a comunidade vem perdendo parte de suas tradições, o que despertou o interesse para o desenvolvimento desta pesquisa.

Dada a diversidade encontrada no local, foi construído um fotolivro como forma de abranger diversas características observadas,

1 Instituição pública do Governo Federal, voltada para promoção e preservação da arte e cultura afro-brasileira (FUNDAÇÃO CULTURAL PALMARES, 2016). 
como seu povo, sua natureza, sua cultura. $\mathrm{O}$ uso da fotografia neste trabalho teve um caráter fundamental, pois esse meio tem um papel de registrar fragmentos da realidade, carregados de signos e símbolos, através da observação realizada pelo fotógrafo. Entre os diversos papéis da fotografia, destaca-se aqui o papel documental, no qual guarda marcas do passado vivido.

A construção do fotolivro surgiu, então, a partir da problemática de como estaria a transmissão dos hábitos e costumes da comunidade de Juçatuba aos seus herdeiros. Para este trabalho, questiono de que maneira a narrativa fotográfica contribui para o fortalecimento das tradições, tendo em vista que pode ser um local de memória e fonte de informação.

Vale destacar que o texto desta pesquisa é apresentado em primeira pessoa por ser o relato da minha experiência de pesquisa, das informações que levantei e das histórias que ouvi e observei ao longo dos meses que passei desenvolvendo o relatório para a conclusão do curso em Comunicação Social - Rádio e TV, na Universidade Federal do Maranhão.

\section{Metodologia}

Esta pesquisa tem uma abordagem qualitativa, o que possibilita uma melhor compreensão do objeto no contexto no qual está inserido, pois "o pesquisador mantém contato direto com o ambiente e o objeto de estudo em questão, necessitando de um trabalho mais intensivo de campo" (PRODANOV; FREITAS, 2013, p. 70). Dessa forma, os procedimentos metodológicos envolveram pesquisa bibliográfica, pesquisa documental, pesquisa de campo 
e pesquisa participante, utilizando entrevistas semiestruturadas, fotografias, documentos da comunidade como material para coleta de dados.

Assim, a pesquisa foi realizada, principalmente, por meio de observação direta, no qual tive a oportunidade de captar explicações e interpretações, tanto por meio dos registros fotográficos (realizados por mim), como também por entrevistas semiestruturadas, conversas informais, diário de campo, além de pesquisas documentais concedidas por alguns moradores de Juçatuba. Ao todo, foram realizadas 10 entrevistas com moradores de Juçatuba, pessoas que nasceram e moram no local e, também, as que nasceram na comunidade, mas moram em São Luís.

O levantamento desse tipo de material permitiu compreender mais sobre Juçatuba. Por meio de entrevistas, por exemplo, foi possível escutar relatos da infância difícil que tiveram os mais velhos, assim como perceber a transição de gerações, divididas entre: os que nasceram e foram criados somente em Juçatuba (onde tiveram uma educação precária, cresceram desenvolvendo atividades agrícolas e continuaram com as tradições); os que nasceram e foram criados fora de Juçatuba, mas voltaram após adultos (esses foram mandados para casas de parentes em São Luís para receber educação e melhores condições de vida); e os que nasceram, moram no local, mas estudam e trabalham na capital (esses moradores têm uma vida mais ligada a São Luís, geralmente saem cedo de casa e voltam durante a noite, além de estarem mais conectados à internet). 


\section{A Comunicação no Cotidiano da \\ Comunidade de Juçatuba}

De acordo com a Vera Veiga França (2001, p. 5) "fechar o objeto da comunicação no campo das mídias é uma operação redutora, ao excluir as inúmeras práticas comunicativas que edificam e marcam a vida social - e não passam pelo terreno das mediações tecnológicas". Dessa maneira, uma das perspectivas apontadas por ela mostra que a comunicação pode ter como objeto de estudos os processos humanos e sociais de produção e circulação de sentidos.

Sodré (2001) também contribui para os estudos da comunicação, trazendo a ideia de vínculo social, ou vinculação humana que, para ele, é um objeto do campo da comunicação. A ideia de vinculação social pode ser entendida como relações estabelecidas entre os sujeitos. Segundo o autor, é uma condição originária do vínculo, anterior à linguagem. Esse afeto não é amor, é algo que é difícil de nomear, não está no campo do gostar ou não gostar. "Isso significa que o afeto é tudo o que escapa à racionalidade instrumentalizada pelo signo, pela palavra" (SODRÉ, 2015, p. 124). É através do afeto que temos uma pré-compreensão do mundo, de forma mais instintiva.

Para Sodré (2001), o termo comunicação remete a dois processos: o de pôr em comum diferenças por meio do discurso e o de interpretar os impactos das tecnologias na sociedade contemporânea. Nessa perspectiva, ao longo da pesquisa de campo, alguns moradores de Juçatuba relataram que a comunidade passou a sofrer mudanças, tanto na infraestrutura do local, como também nos costumes, a partir da construção da estrada, que possibilitou o acesso a serviços, como 
energia elétrica, telefone e transporte público.

A introdução desses objetos técnicos (e de outros a partir desses, como televisão, smartphones, geladeira) trouxe modificações significativas a partir do estabelecimento de um vínculo entre esses objetos e o sujeito, como observa Sodré (2015, p. 125). Para ele, "A máquina hoje é sujeito social também, desde o sinal de trânsito à televisão, ao computador. Nós entramos num diálogo real com as máquinas, com esse negócio de se fotografar o tempo inteiro, mandar mensagens". É a partir dessas relações de afeto que as percepções, as formas como entendemos o mundo, são produzidas, de maneira que podem mudar nossas ações do cotidiano.

É por meio da vinculação social, dos estudos voltados para a interação social que se tem outros caminhos para estudar temas que envolvem cultura, tradições e cotidiano como questões da comunicação. Braga (2011) apresenta essa ideia a partir do conceito de auto-explicitação do gesto cultural, que acontece quando as pessoas ou grupos já não realizam suas atividades apenas porque é algo deixado pelos antepassados, passando a fazer aquelas atividades de forma consciente. "Quando a cultura se percebe cultura, quando o gesto que faço não pode mais se justificar como se fosse 'natural' através de um 'é assim que se faz' - já não estamos exclusivamente no território da cultura, mas também no da Comunicação". (BRAGA, 2011, p. 75)

Nessa linha, ao longo da pesquisa de campo foi possível ouvir o relato de alguns moradores a respeito do cotidiano e dos costumes do local. Alguns hábitos simples, como o de jogar lixo no quintal e queimar, foram sendo deixados de lado depois que a coleta começou a ser feita pela prefeitura de São José de Ribamar. Hoje, 
quem ainda mantém esse hábito não é visto com bons olhos. Além disso, houve mudanças também no modo de vida a partir do momento que os pais passaram a mandar seus filhos para São Luís, buscando melhores condições de estudo e vida. A cultura da agricultura foi diminuindo, passando a não ser mais o único modo de sobrevivência dos moradores. Atualmente, poucos são os agricultores do local, mas a maioria permanece com a atividade como forma de adquirir renda para sustentar a família.

Mas eu acho que o que tá pegando eu acho que a maioria relaxaram um pouco (trabalhar em roça) [...] uns pegaram serviço, outros se invocaram mais no estudo, serviço, até porque as coisas evoluíram muito né. [...] Hoje muitos não querem trabalhar e os que querem não têm recurso. [...] Eu trabalho em feira e não paro de fazer da roça. Eu não paro de trabalhar porque na minha época eu não tive oportunidade de estudar, estudei bem pouco, estudo aqui era no máximo até a $4^{a}$ série, recurso pra nós estudar lá fora não tinha, hoje tá tudo fácil. Hoje tem dois ônibus, é difícil uma casa não ter moto. [...] Hoje tem você que é jovem, tem meu filho que é jovem, tá na faculdade, mas a gente não teve essa oportunidade, não foi porque a gente não quis, foi porque a gente não teve essa oportunidade. (Informação verbal) ${ }^{2}$

É por meio da comunicação que as relações sociais ficam mais concretas e a cultura se estabelece e se modifica, levando em consideração que ela está em processo constante de mudança. Essa mudança pode ser atribuída às tecnologias digitais de comunicação que cada vez mais tem alterado as formas de relações sociais, além

2 Depoimento de João (nome fictício dado a pedido do entrevistado) concedido ao autor, durante pesquisa de campo na comunidade pesquisada. 
de alterar a relação com o tempo. A velocidade com que circulam as informações modificam a experiência de tempo, produzindo outra temporalidade, chamada de tempo real, conforme sugere Sodré (2007, p. 19):

De fato, num mundo posto em rede técnica, modificase profundamente a experiência habitual do tempo: virtualmente conectado a todos os outros, cada indivíduo pode ser alcançado sem demora, nem período marcado, por qualquer um. Isto é precisamente o «tempo real», ou seja, a abolição dos prazos, assim como dos tempos mortos (a reciclagem do ócio pelo sistema de informação) pelos dispositivos técnicos integrados em nossa ambiência cotidiana.

Ao voltar para o objeto de estudo deste trabalho, vemos que Juçatuba também passou por mudanças com a inserção de tecnologias digitais no seu cotidiano. Ao longo da pesquisa exploratória foi possível ouvir, a partir de relatos de moradores, como algumas atividades tradicionais do local foram sendo deixados de lado pelos mais jovens.

Por que acabou? Os mais velhos foram ficando velhos e foram ficando velhos e sem condições. Os filhos já puxaram pra estudar e pegar um serviço lá fora pra sair do sol, da chuva, do bruto aqui. Aqui em casa, como já the falei, eu me casei com um lavrador, fazedor de roça, fazedor de farinha, os filhos tudinho, mas quem disse pra João ir cavar uma roça, plantar mandioca. Ele não sabe fazer os buracos, ele vai cavar de uma forma, seja lá como for, mas ele não sabe como é. [...] Hoje eu tenho um neto aqui de 19 anos, o pai dele foi um trabalhador de roça, mas já ele... tô cansada de pedir pra ele capinar esse

3 Nome fictício para preservar identidade do entrevistado. 
capim aqui na porta. Ele diz que não sabe capinar. (Informação verbal) ${ }^{4}$

A comunicação desempenha um importante papel nos processos humanos e sociais. Ela contribui na análise da forma de transmissão da tradição ao longo do tempo, assim como das mudanças que ocorrem no cotidiano de um povo, após a inserção de tecnologias digitais de informação ou de meios técnicos.

Além disso, a comunicação exerce também o papel de fazer refletir sobre os modos de vida desse povo, devido ao presente indicar também situações do passado, a partir do entrelaçamento deles, como coloca Barbosa (2009, p. 13) "O que se faz em comunicação é colocar em evidência os processos comunicacionais numa época comum, o presente vivido, para tentar explicar não apenas essas narrativas, mas compreender as ações desses homens no presente".

Nessa perspectiva, o uso da imagem fotográfica, como suporte de comunicação, é essencial para essa reflexão sobre o cotidiano, visto que deixa estático um dado momento da realidade que registra os modos de vida em um dado momento da história.

Todas essas imagens nos levam a resgatar o prazer do instante, do momento presente e do ausente, daquilo que passou, mas que permanece na memória. Olhamos para fotografias para resgatar o passado no presente. Tiramos fotografias para nos apropriarmos do objeto que desaparecerá. Existe uma magia quando imortalizamos as pessoas e o tempo nas fotos. Para as tribos urbanas, fotografias são como provas de sua existência, de sua identidade e história. (ANDRADE, 2002, p. 49)

4 Depoimento de Maria (nome fictício dado a pedido do entrevistado) concedido ao autor, durante pesquisa de campo na comunidade pesquisada. 
A fotografia, então, exerce um papel fundamental para a sociedade, tanto como um meio de comunicação (dado que é carregada de símbolos e índices ${ }^{5}$ ), como também de espelho da memória, por imortalizar aquele momento para sempre.

\section{Imagem Fotográfica como Fonte de Informação}

De acordo com Tomas William Mendoza-Harrell (2002), a fotografia representa o detalhe, a minúcia, a perspectiva, a luz, o momento fugaz, a espontaneidade e a verdade. Um meio carregado de informação, que não é puramente resultado apenas de um processo químico e físico, mas também uma imagem dotada de sensibilidade estética, resultado do olhar atento e singular do fotógrafo.

A utilização da fotografia para a realização deste trabalho se deu tanto pelo desenvolvimento de estudos ao longo da graduação nesta área de conhecimento, como também porque possibilita o acesso ao trabalho por públicos diversos, seja pela comunidade acadêmica, ou por leigos que se interessam pelo assunto.

A fotografia usada como dispositivo de linguagem acadêmica cria a possibilidade de maior propagação dos estudos através do uso indiscriminado destas narrativas imagéticas. Isso quer dizer que a fotografia representa uma facilidade no sentido de fazer com que o trabalho acadêmico possa transitar não só nas outras áreas do conhecimento que não as ciências sociais, como também entre o público leigo que

5 Símbolo é algo convencionado culturalmente, ou seja, sua leitura depende de um conhecimento prévio dos códigos que ali se tem; enquanto o índice é marcado pelo referente ao real, ou seja, é um traço da realidade. (DUBOIS, 1993) 
venha a se interessar sobre o assunto. (SALVAGNI; SILVEIRA, 2013, p. 2)

Dessa maneira, acredito que o uso da linguagem nãoverbal $^{6}$ (imagem fotográfica) facilita também o acesso, a leitura e o entendimento desta pesquisa por todos na comunidade de Juçatuba. Para Collier (1973), pesamos com imagens e, muitas das vezes, nos comunicamos com imagens, o que facilita uma rápida compreensão das mensagens visuais.

Em toda a vida moderna se percebe o efeito da fotografia como um aspecto da realidade. Num certo sentido pensamos fotograficamente, e certamente nos comunicamos fotograficamente. A linguagem nãoverbal do realismo fotográfico é a mais entendida inter e transculturalmente. Esta facilidade de reconhecimento é a razão básica para a câmara ter tal importância antropológica. (COLLIER, 1973, p. 6)

Além disso, os registros fotográficos, do gênero documental, representam um meio de informação, de conhecimento, com um valor documental e iconográfico (KOSSOY, 2012). Porém, esse uso da fotografia como meio de informação e documento ou meio de expressão do sujeito não foi atribuída logo de início. Ao longo do tempo, a fotografia foi adquirindo diversos papéis, sendo inclusive creditada de realidade.

Estima-se que a fotografia tenha sido iniciada em 1826, quando 0 francês Joseph Nicephore Niepce conseguiu fazer a 6 Em um trabalho de construção simbólica, Corrêa (2002) relata o tipo de suporte como principal diferença entre a linguagem verbal e a não-verbal. Enquanto o som e a escrita são traços da linguagem verbal, diversos tipos de linguagem não-verbal são encontrados, como grafismo das artes plásticas, etc. Além disso, esse texto visual é dotado de uma narrativa, enunciado e, dessa forma, é um meio de comunicação. 
primeira fotografia durável do mundo, através do processo chamado de Heliografia. A técnica, porém, tinha um tempo de fixação muito longo, e logo foi aperfeiçoada em 1839, com a Daguerreotipia, criada por Jaques Dandé Daguerre.

Mas a fotografia alcança uma popularidade mundial apenas através de George Eastman, em 1888, com a Eastman Kodak Company e a introdução de filmes em rolos e uma pequena câmera de caixinha no mercado. A partir de então, o ato de fotografar foi espalhado por todo mundo, criando diversos gêneros fotográficos além do retrato e da fotografia científica.

A partir de então a fotografia passou a chamar maior atenção de todos, inclusive de pesquisadores da área das sociais. De acordo com Novaes (2012), a fotografia foi e é de grande interesse inclusive de antropólogos, no sentido de registrar fatos que ocorrem na vida social e aprender sobre as diferenças de raça e condição social. A fotografia até hoje tem o papel ser um registro simbólico do cotidiano, utilizado tanto pela ciência, quanto pela sociedade em geral para registro de eventos em família, retratos, por exemplo (SALVAGNI; SILVEIRA. 2013).

Logo no final do século XVIII o interesse pela fotografia foi despertado em antropólogos, que passaram a se utilizar desse instrumento ao longo das pesquisas de campo, seja como um suporte para observações posteriores, ou como um material capaz de descrever o que não conseguimos em palavras.

"Importa perceber o quanto a fotografia aparece como recurso estratégico que se alia ao caderno de campo, permitindo registrar o que dificilmente conseguimos descrever em palavras, seja pela densidade visual daquilo que registramos, seja por seu aspecto 
mais sensível e emocional" (NOVAES, 2012, p. 13).

Por diversos anos a fotografia foi vista como algo real por sua capacidade de representar o mundo com grande semelhança, sendo utilizada em diversas ciências, ou como provas de crimes, ou mesmo em documentos. Porém, para alguns autores, como Mauad (1996), a fotografia é uma leitura do real, um importante instrumento de análise e interpretação, e não a realidade propriamente dita. Características como sua forma bidimensional, isolamento de um ponto no tempo/espaço e limitações sensoriais mostram como a fotografia não é real, segundo a autora. Assim, é possível compreender a imagem fotográfica, não como a realidade em si, mas como "uma realidade revelada, resgatada, atingida, e para alguns, até roubada". (ANDRADE, 2002, p. 41)

Porém, de acordo com o filósofo e historiador, DidiHuberman (2012, p. 213), a imagem é muito além de apenas um recorte da realidade. Ela carrega em si uma [...] impressão, um rastro, um traço visual do tempo que quis tocar, mas também de outros tempos suplementares - fatalmente anacrônicos, heterogêneos entre eles - que não pode, como arte da memória, não pode aglutinar.

Dessa maneira, concebo a imagem como um conjunto de símbolos, que podem fazer referência não só ao tempo presente, mas também a experiências vividas. Segundo Didi-Huberman (2012), as relações de tempo são percebidas na própria imagem, pois nela estão um conjunto dessas relações, na qual o presente também se encontra. Na imagem essa questão de tempo se torna visível, sensível e irredutível ao presente. As imagens realizadas no tempo atual podem, também, carregar símbolos de tempos passados, que podem auxiliar na compreensão do presente e nos fazem pensar também no 
futuro.

De acordo com Kossoy (2012, p. 48), a partir do clique dado pelo fotógrafo, o instante é isolado e interrompido. Aqui, inicia-se uma segunda realidade, chamada de documento, e caracterizada por ser autônoma. A imagem fotográfica então, além de ter um valor estético, reúne diversas informações daquele fragmento do espaço/ tempo retratado. "O artefato fotográfico, através da matéria (que lhe dá o corpo) e de sua expressão (o registro visual nele contido), constitui uma fonte histórica". É possível ainda pensar que esse conteúdo registrado, ainda que não possua a característica de fato histórico, ganha a função de memória, quando transformado em documento para o futuro. (BARBOSA, 2016, p. 12)

Além disso, a fotografia, como meio de informação, também modifica nossa relação com o espaço-tempo, por meio do registro de imagens que carregam símbolos que remetem a um tempo passado, garantindo uma preservação da memória. "Num jogo de libertações, novas próteses possibilitam a multiplicação dos atos memoráveis, fazendo com que a memória seja algo mais do que a possibilidade de armazenar informações na mente humana: a memória se transforma em documento". (BARBOSA, 2012, p. 150)

É possível pensar a imagem fotográfica também como agente da construção de discursos de memória, pois as imagens nos remontam a um instante, um momento que passou. "Olhamos para fotografias para resgatar o passado no presente. Tiramos fotografias para nos apropriarmos do objeto que desaparecerá". (ANDRADE, 2002, p. 49).

A fotografia passou por três percursos ao longo da história sobre a questão do realismo, sendo vista primeiro como um espelho 
do real, ou seja, uma imitação mais perfeita da realidade; uma transformação da realidade: a fotografia não é mais uma representação perfeita do real, mas um registro bidimensional de um acontecimento, enquadrado sob a perspectiva do olhar do fotógrafo, em um momento isolado no tempo/espaço com códigos culturalmente convencionados (símbolos); e, por fim, como um traço do real, a imagem é um referente com valor particular, com um sentido exterior à composição, ou seja, "as fotografia propriamente ditas quase não tem significação nelas mesmas: seu sentido lhes é exterior, é essencialmente determinado por sua relação efetiva com o seu objeto e com sua situação de enunciação". (DUBOIS, 1993, p. 52).

Nessa perspectiva, é possível relacionar a fotografia (como índice) com a memória, tendo em vista que ela é um meio de conhecimento, que documenta e permite o conhecimento das diversidades do mundo, permite que no presente se olhe para o passado e dessa maneira, se projete ações para o futuro. (BARBOSA, 2012).

Imagem 1- Cruzeiro e fachada da igreja católica em 2014

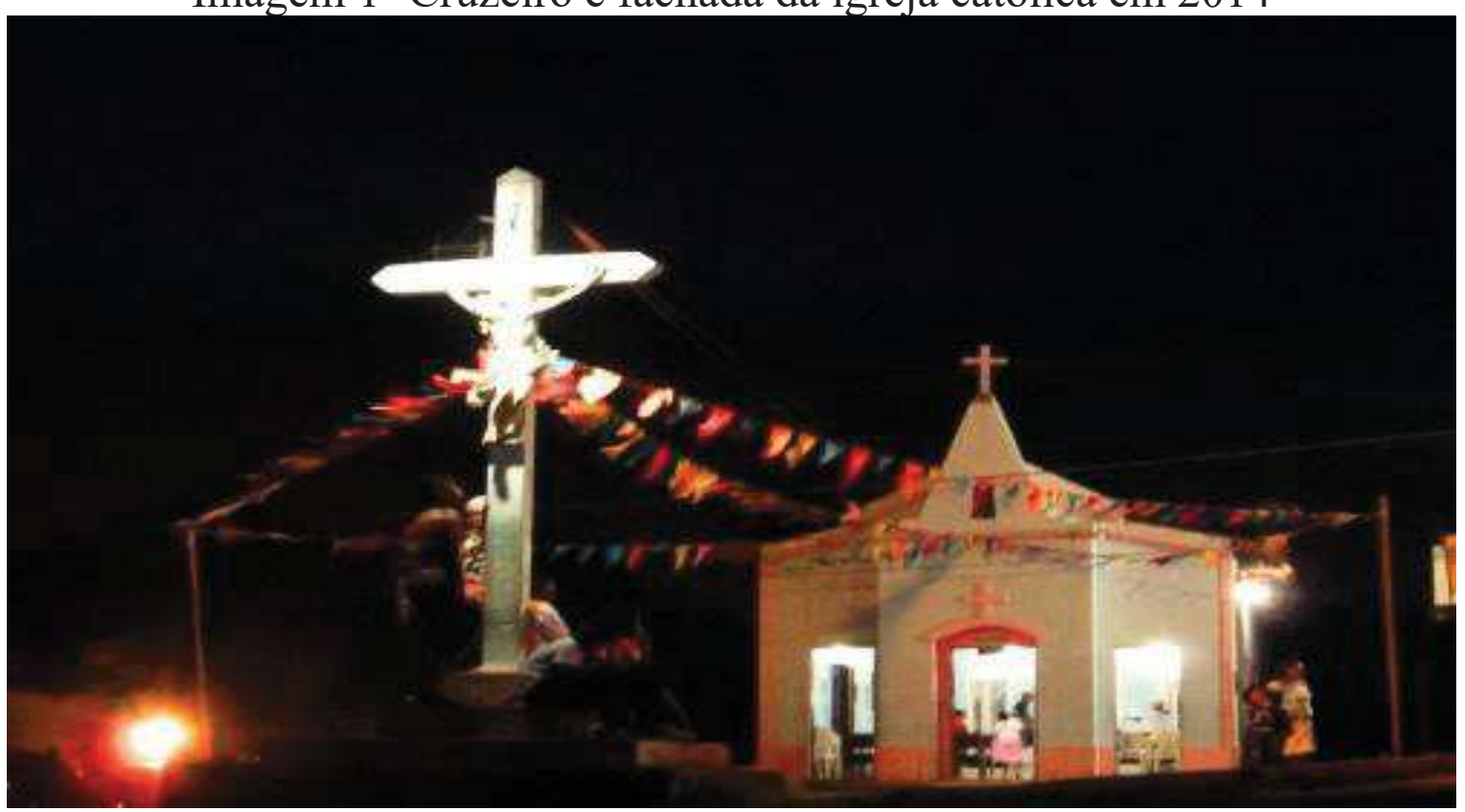

Fonte: Arquivo pessoal 
Imagem 2 - Cruzeiro e fachada da igreja católica em abril de 2018

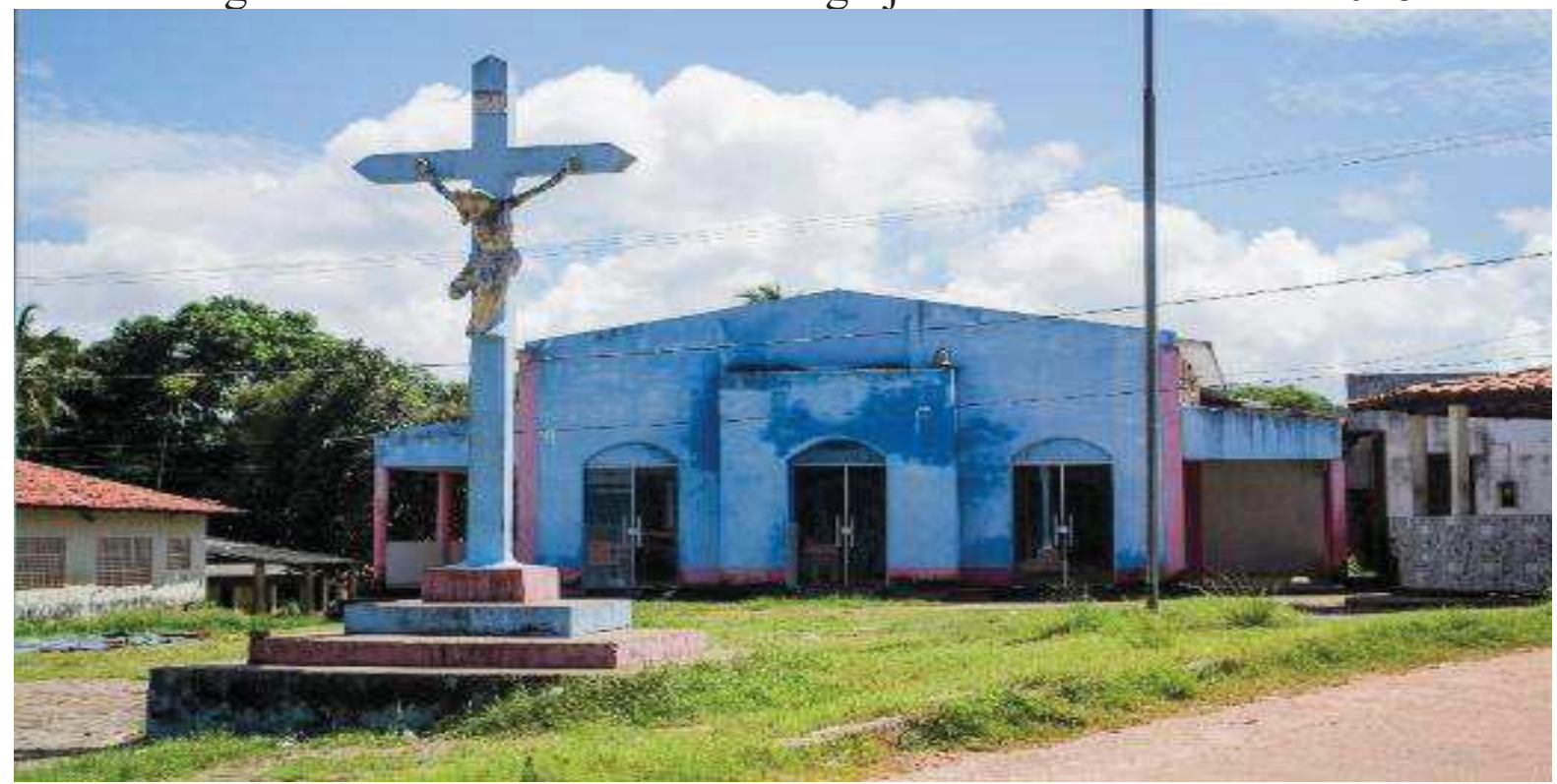

Fonte: Arquivo pessoal

Acima, temos duas fotografias com índices importantes para a comunidade de Juçatuba, uma vez que o local tem uma tradição muito forte com a religiosidade e a fé na santa padroeira do local, Nossa Senhora Mãe dos Homens. Na imagem 1, temos um registro da igreja católica feito em 2014, que revela uma parte da história da comunidade e também pode atuar como um ponto de memória para aqueles que tiveram alguma relação direta ou indireta com o local. $\mathrm{Na}$ imagem 2, temos um registro realizado ao longo da pesquisa de campo, que nos mostra o cenário atual da comunidade naquele momento e as transformações que vêm ocorrendo em Juçatuba.

É nesse conjunto de informações que são estabelecidas pontes entre o sujeito e os índices presentes na imagem fotográfica, que permitem a quem ver a fotografia um significado, de acordo com sua bagagem cultural. Isso tem impacto na construção e na autoafirmação da identidade individual, tendo em vista que ao se constituir como lugar de memória, tem o papel de ser um espaço 
para a articulação de memória coletiva de um determinado grupo. (BARBOSA, 2016, p. 11).

Nessa perspectiva, "a imagem fotográfica é o que resta do acontecimento, fragmento congelado de uma realidade passada, informação maior de vida e morte [...]" (KOSSOY, 2012, p. 39). A imagem, produzida a partir da técnica fotográfica, pode exercer um papel de registro da memória de um povo.

Existe, portanto, algo de lúdico na fotografia que é capaz de ocupar o espaço de imortalizador daquela cena, momento, sociedade ou mesmo de uma fase da vida de alguém. Especialmente em se tratando de uma fotografia documental, é justamente naquele momento compreendido como banal da rotina dos respondentes que pode vir a se transformar num importante item da memória da sociedade, possibilitando que a vida cotidiana possa vir a se transformar em um tipo de arte que está a serviço da pesquisa (SALVAGNI; SILVEIRA, 2013, p. 3)

Segundo Barthes (2015), essa imagem fotográfica não representa aquilo que não é mais, mas atesta que algum dia algo já existiu ali. "A fotografia não rememora o passado (não há nada de proustiano em uma foto). $\mathrm{O}$ efeito que ela produz em mim não é o de restituir o que é abolido (pelo tempo, pela distância), mas o de atestar que o que vejo de fato existiu". (BARTHES, 2015, p. 71).

Ao longo da pesquisa de campo em Juçatuba, foi possível perceber a importância dos registros do cotidiano e das tradições em fotografias, como forma de guardar esses acontecimentos e não deixá-los cair no esquecimento. Um dos entrevistados, inclusive, enfatiza que se houvesse mais registros materiais da história do 
local, talvez haveria uma valorização maior dos costumes locais, pois seria um meio de atestar os hábitos dos antepassados e também as dificuldades enfrentadas.

A gente queria ter um vídeo, né, filmado para mostrar pra você pra te ver até quando eu vim pra cá, pra essa casa aqui, a minha casa era lá embaixo perto do campo era de taipa. Nem celular bom aqui no Satuba não tinha pra chegar e filmar pa hoje nós mostrar pra vocês: aí ó, assim que era a casa de papai e mamãe aqui'. Como em muito interior isolado que passa em televisão as casas tudo de taipa, assim que era aqui [...] Eu queria ter hoje um vídeo, como tem hoje, tá tudo avançado né, pra mostrar pra vocês como foi nosso sofrimento, era areia, era estrada. Te lembra como no inverno Mariano tinha que sair daqui como o pessoal mais velho, eu era criança, o pessoal mais velho saia daqui era cedo pra tá no João Paulo porque o caminho daqui era só lama, chovia aí atolava. Pessoal ia só com um calçãozinho pra empurrar quando atolava. Pena que a gente não tem essa recordação, que é pra mostrar pra juventude [...] Tu puxou um assunto muito importante que eu puxei há poucos dias pra João e Alan, que será que aqui não dá pra reunir um grupo de jovens pra escrever, ou ao menos tentar escrever um livro falando sobre o nosso lugar porque tem muita coisa boa. [...] Chama aquelas pessoas dos mais velhos pra escrever o que foi o que achou no lugar e completa com a juventude. (Informação verbal) ${ }^{7}$

A imagem fotográfica, como fonte de informação e um local de memória, apresenta um papel fundamental para a sociedade, pois é um suporte que tem um poder de atestar que as formas de sobrevivência, as tradições locais e os hábitos de uma comunidade 7 Depoimento de João (nome fictício dado a pedido do entrevistado) concedido ao autor, durante pesquisa de campo na comunidade pesquisada. 
existem. Além disso, podem trazer ao sujeito uma reflexão acerca do seu cotidiano, a partir de elementos que remetem ao passado, e assim modificando seu futuro.

\section{Fotolivro: "Juçatuba: Cotidiano e Tradições"}

Utilizar as fotografias como suporte principal para refletir sobre a transmissão dos hábitos e costumes da comunidade Juçatuba foi essencial, devido à imagem fotográfica conseguir capturar um volume de informações que muitas vezes por palavras não poderiam ser ditas.

As fotografias igualmente permitem registrar aquilo que em palavras perde toda a sua intensidade e dramaticidade, [...]. Finalmente, a fotografia sempre significou, para mim, a possibilidade de registrar uma estética visual da qual esta sociedade muito se orgulha e que dificilmente conseguiria descrever verbalmente. (NOVAES, 2012, p. 21)

Da mesma maneira, a utilização das fotografias para a construção deste trabalho, permitiu uma liberdade maior para transmitir minha visão sobre os acontecimentos, tal como eles eram passados, codificados em signos e símbolos, que remontam ao que é Juçatuba, ao que o povo dessa comunidade mantém até os dias de hoje.

Na perspectiva de Salvagni e Silveira (2013), a organização das imagens separado do texto da pesquisa permite a ênfase sobre a reflexão do autor com a imagem, nos possibilitando, além de uma percepção própria, a do próprio leitor explicar a intenção da imagem, 
através de elementos, como luz, cena, enquadramento, etc.

Assim, optei por construir um fotolivro que reunisse todas essas percepções de campo, desenvolvidas ao longo de meses. $\mathrm{Na}$ definição de Barbosa (2013), um fotolivro é caracterizado pela organização de um conjunto de fotografias tendo em vista uma narrativa iconográfica capaz de transmitir um discurso visual. São produtos de circulação de ideias, resultado de um projeto estético, cultural e político.

A reunião dessas imagens fotográficas deu origem ao fotolivro, intitulado "Juçatuba: cotidiano e tradições", que traz desde os dias mais simples na comunidade, até dias festivos, como a morte do bumba meu boi de Juçatuba e o festejo de Nossa Senhora Mãe dos Homens.

Imagem 3 - Capa e verso do fotolivro "Juçatuba: cotidiano e tradições"

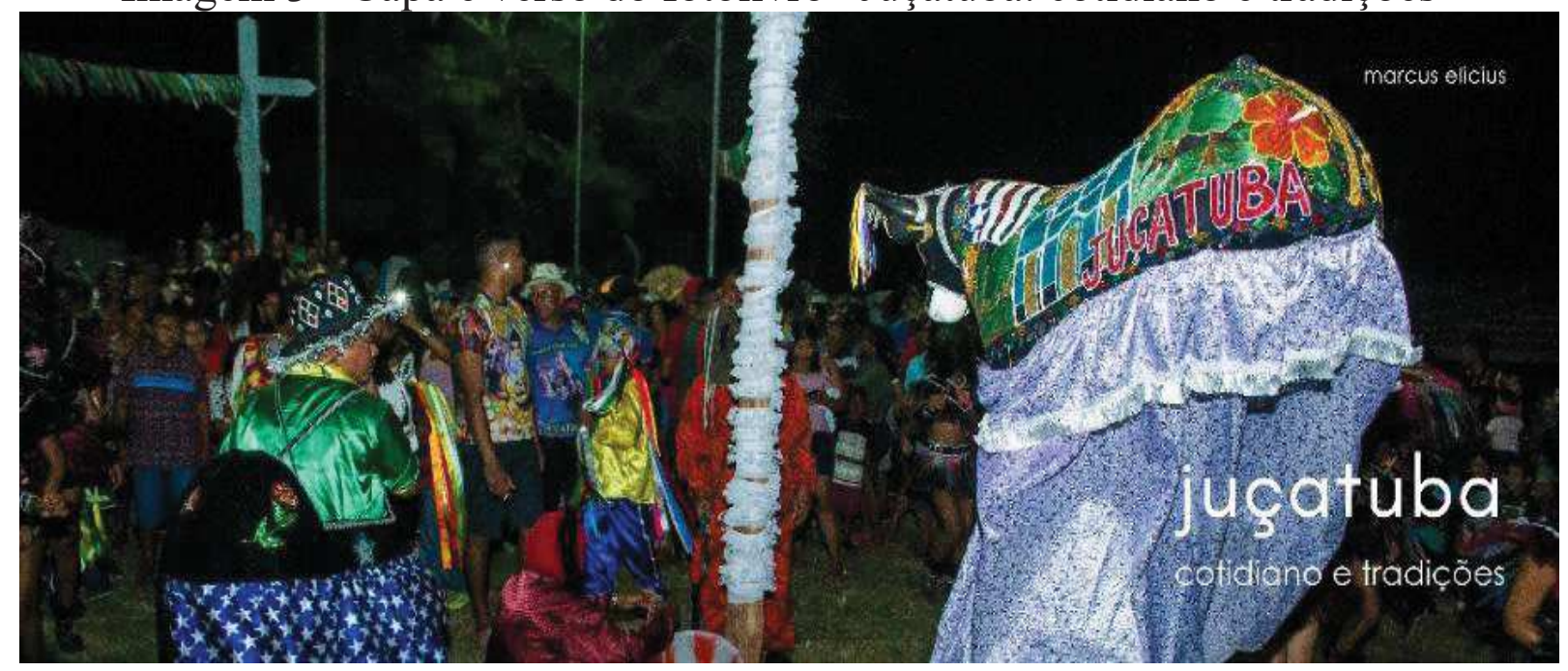

Fonte: Arquivo pessoal

A fotografia aqui também teve importância por facilitar o acesso no conhecimento de culturas diferentes, sem prejuízo no entendimento geral do leitor, pois a compreensão da imagem 
fotográfica se dá a partir de regras culturais, com significados coletivos e não só individuais, como explica Mauad (1996, p. 79):

\begin{abstract}
Nessa perspectiva, a fotografia é interpretada como resultado de um trabalho social de produção de sentido, pautado sobre códigos convencionalizados culturalmente. É uma mensagem, que se processa através do tempo, cujas unidades constituintes são culturais, mas assumem funções sígnicas diferenciadas, de acordo com o contexto no qual a mensagem é veiculada, quanto com o local que ocupam no interior da própria mensagem.
\end{abstract}

Para nortear a leitura das imagens, trouxe no fotolivro citações de algumas falas ditas por pessoas que entrevistei e conversei ao longo da pesquisa de campo, de maneira que também contribuísse para o despertar de algumas memórias dos moradores. "E, de todo modo, a ênfase na dialética entre imagem e a palavra é o embasamento da construção social da realidade que busca iluminar memórias, reminiscências e particularidades dos sujeitos estudados". (SALVAGNI; SILVEIRA. 2013, p. 3)

Na composição do fotolivro, decidiutilizar, além das imagens do cotidiano, fotografias de eventos tradicionais da comunidade. Para isso, foi preciso organizar um cronograma, contendo os dias para realização dos ensaios. Nesse cronograma, foram elencados os principais locais de Juçatuba, os festejos que poderiam ser incluídos no roteiro. Dessa forma, participei do pagamento de uma promessa, do início e fim do festejo do Divino Espírito Santo, ensaios e morte do bumba meu boi de Juçatuba, festejo de Nossa Senhora Mãe dos Homens (padroeira de Juçatuba) e o dia de finados. Esses eventos foram selecionados por serem datas significativas para Juçatuba, 
que se mostrou ligada ainda aos costumes religiosos, e também por coincidirem com o período de pesquisa, realizado de abril a novembro de 2018.

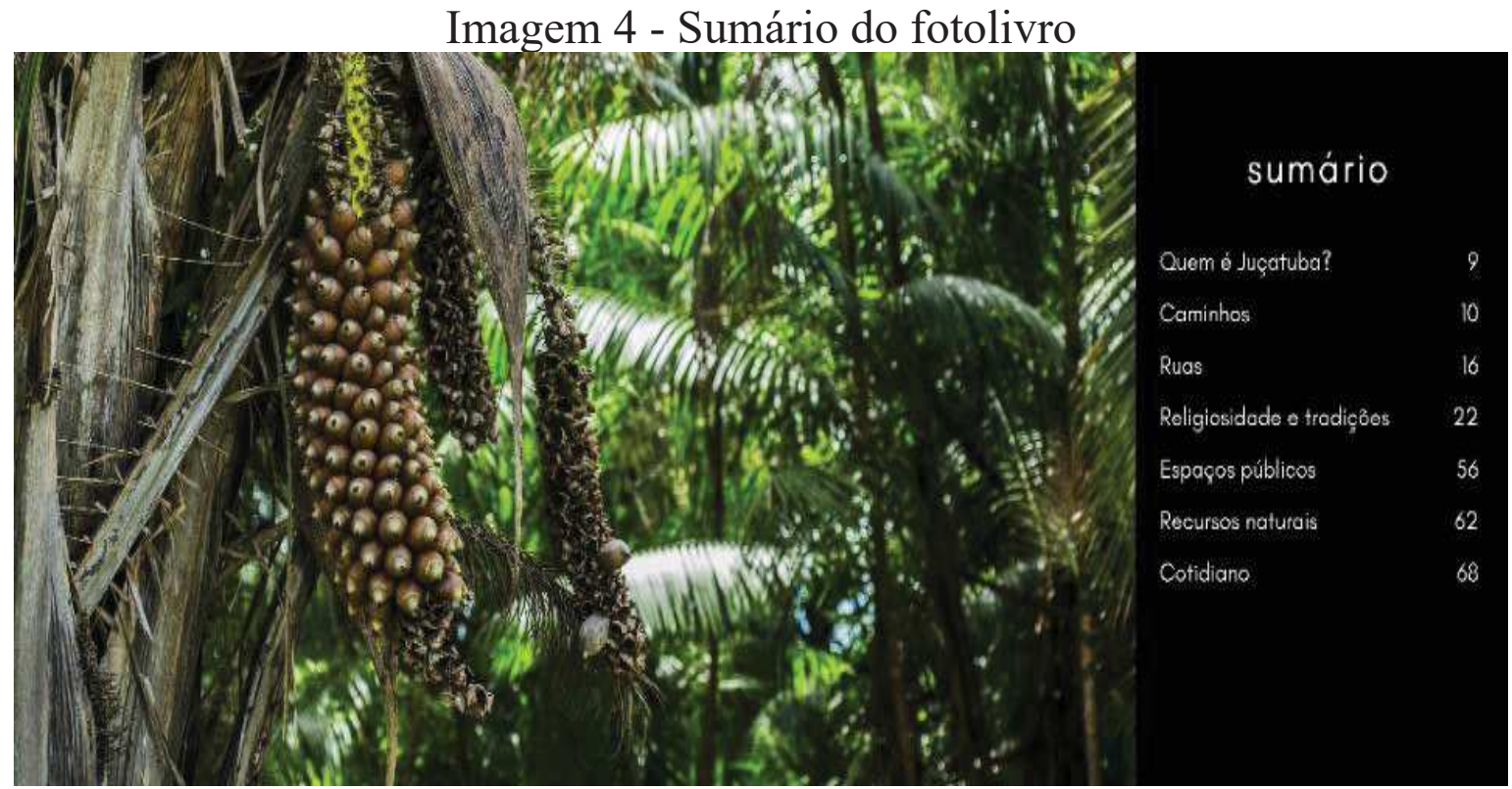

Fonte: Arquivo pessoal

Foram realizados 12 ensaios, ao longo dos 7 meses que pesquisei na comunidade, com uma média de 500 imagens por ensaio, o que resultou em mais de 40 gigabytes de material fotografado. A seleção delas envolveu o longo processo de reflexão sobre a representatividade para o que se constitui como cotidiano e tradições de Juçatuba. "Neste sentido, cabe ao pesquisador plena consciência das imagens que ele quer ver publicadas a respeito das pessoas que pesquisa. [...] Suas imagens contribuirão certamente para a imagem que se terá daquele povo". (NOVAES, 2012, p. 27). 
Imagem 5 - Folha do capítulo "Religiosidade e tradições", do fotolivro

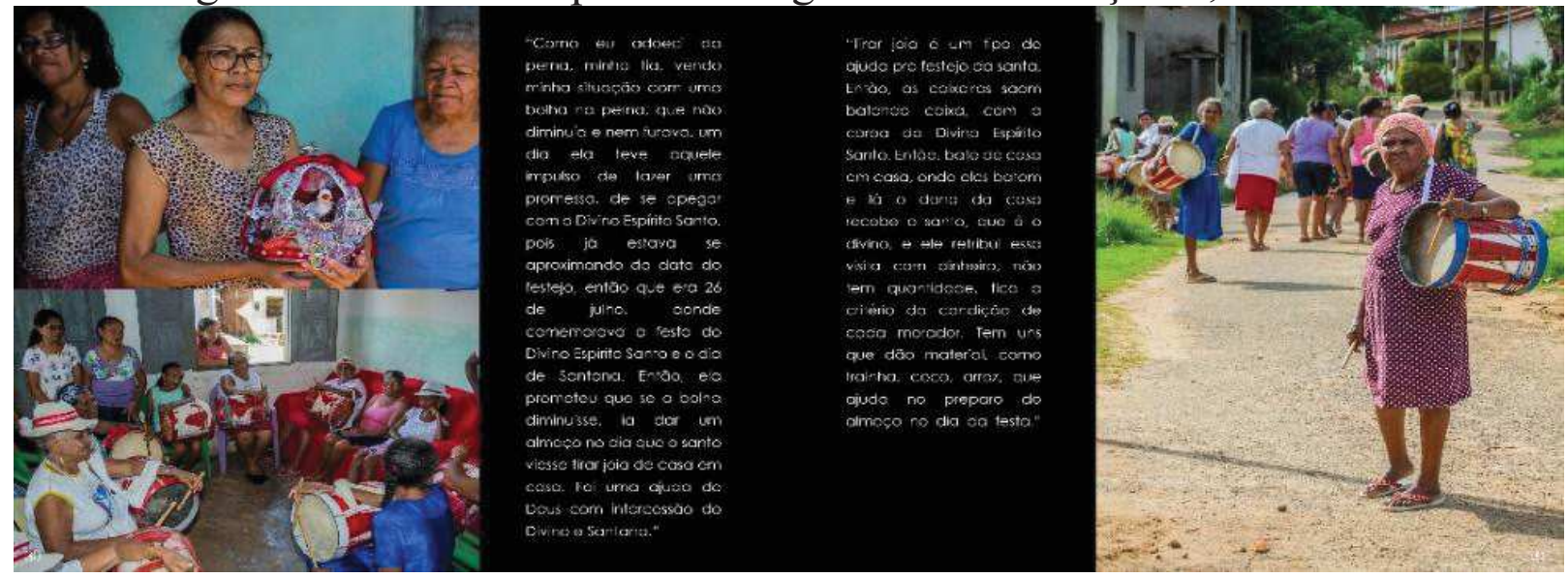

Fonte: Arquivo pessoal

Assim, a seleção das imagens foi cautelosa, pois o fotolivro tem uma importância para a comunidade, no sentido de fazer os moradores de Juçatuba olharem sua imagem e se reconhecerem nelas, tomando consciência da herança deixada por seus antepassados, numa tentativa de preservar as tradições do local, que tem sido perdida, de acordo com os próprios habitantes. Além disso, este trabalho tem o papel fundamental como material de pesquisa para aqueles que buscam conhecer mais sobre Juçatuba, com um agrupamento de informações de cunho documental e histórico.

A fotografia nutre a sua interpretação por uma contínua remessa ao real, que não se deixa congelar, que não interrompe o seu fluxo e que, por sua vez, agrega e redefine significações ao que só aparentemente é um "congelamento" de imagem e, nesse sentido, um "retrato" da sociedade em certo momento. [...] a fotografia tece uma história. Revela-se o oposto do "congelamento", entrosa-se dinamicamente nas necessidades do processo social". (MARTINS, 2008, p. 37). 
O fotolivro, como uma narrativa sobre Juçatuba, tem ainda importância de divulgar essa comunidade, que por muito foi esquecida, mas que cresceu com resiliência e uma vida simples, preservando alguns costumes e se moldando em outros.

\section{Considerações Finais}

Ao longo da pesquisa, tive uma inquietação sobre como estaria a transmissão dos hábitos e as tradições da comunidade de Juçatuba, supondo que os moradores estariam deixando de transmitir as tradições, por conta da urbanização (construção da estrada de acesso, chegada da energia elétrica) e a vida dos herdeiros da comunidade estarem mais atrelada à cidade de São Luís. Busquei refletir sobre como estava ocorrendo essa transmissão, de maneira a registrar minhas observações através de fotografias e organizá-las em um fotolivro.

Para isso, foi preciso enfatizar a importância da comunicação nesta pesquisa no estudo dos processos humanos e sociais, como objeto da comunicação, sendo importante para a análise de como os moradores se relacionam com objetos eletrônicos e as tecnologias digitais de comunicação e como elas influenciaram no modo de vida dessa comunidade.

Conforme observado ao longo deste trabalho, Juçatuba passou por transformações que modificaram sua relação com as tradições no cotidiano. Os mais jovens, agora, têm sua atenção dividida entre as tradições deixadas pelos seus pais e avós, e uma cultura global, acessada através da internet, por meio de celulares e computadores. 
A reflexão sobre a imagem e seu poder de fonte de informação e de local de memória deram suporte para mostrar como as fotografias documentais são importantes para pesquisas deste tipo, pois elas são registros de tradições e acontecimentos do cotidiano, sendo produto documental e histórico. Elas facilitam o acesso aos conhecimentos produzidos, de maneira a fazer conhecer diferentes povos e culturas. Para a comunidade estudada, a fotografia tem um papel fundamental, sendo observada como um elemento de preservação de memórias e como forma de valorização das tradições locais.

Ao mostrar os primeiros esboços do fotolivro para alguns moradores de Juçatuba, percebi também como as imagens fotográficas registradas atuam como ponto de memória, no resgate de outras imagens mentais da vivência deles. Ao ver algumas imagens da praia, um dos moradores recordou que antigamente o lugar tinha a função de pescaria para subsistência, não sendo tão vista como um local de lazer, como é mais observado hoje. Esse relato demonstra algum dos impactos deste trabalho para a comunidade.

O resultado do registro dessas observações, foi o fotolivro "Juçatuba: cotidiano e tradições", meu trabalho de conclusão do curso de Comunicação Social - Rádio e TV (UFMA), que traz um leque de informações sobre essa comunidade rica em vários sentidos, desde cultural à natureza, mas que tem perdido isso no decorrer do tempo. O fotolivro tem o papel também de fazer os moradores refletirem sobre como está sendo, como era e como pode ser a transmissão das tradições culturais e religiosas, de forma a manter e perpetuálas. Além disso, esse material tem o papel de servir como fonte de informação sobre Juçatuba, que ainda tem boa parte de sua história 
na oralidade.

\section{Referências}

ANDRADE, Rosane de. Fotografia e antropologia: olhares foradentro. São Paulo: Estação da Liberdade: EUDC, 2002.

BARBOSA, Carlos A. S. Fotolivros e história comparada da fotografia na América Latina: reflexões teóricas e possibilidades de investigação. In: ENCONTRO NACIONAL DE ESTUDOS DA IMAGEM, 4.; ENCONTRO INTERNACIONAL DE ESTUDOS DA IMAGEM, 1., 2013, Londrina, PR. Anais [...]. Londrina: LEDI/UEL, 2013. CD-ROM.

BARBOSA, Marialva. Comunicação e história: presente e passado em atos narrativos. Comunicação, Mídia e Consumo, São Paulo, SP, v. 6, n. 16, p. 11-27, jul. 2009. Disponível em: http:// http:// revistacmc.espm.br/index.php/revistacmc/article/view/154/155. Acesso em: 8 jul. 2017.

BARBOSA, Marialva. O presente e o passado como processo comunicacional. São Paulo: Matrizes, 2012. v. 5, p. 145-155.

BARBOSA, Marialva. Meios de Comunicação: lugar de memória ou na história?. Contracampo, v. 35, n. 1, 2016.

BARTHES, Roland. A câmara clara: nota sobre a fotografia. Tradução de Júlio Castañon Guimarães. Rio de Janeiro: Nova Fronteira, 2015. Ed. especial.

BRAGA, José Luiz. Constituição do campo da comunicação. Verso e Reverso, São Leopoldo, RS, v. 25, n. 58, p. 62-77, jan. /abr. 2011.

COLLIER, John. Antropologia visual: a fotografia como método de pesquisa. Tradução de Iara Ferraz e Solange Martins Couceiro. 
São Paulo: EPU: Ed. da Universidade de São Paulo, 1973.

CORREAA, Manoel Luiz Gonçalves. Linguagem e comunicação social: visões da linguística moderna. São Paulo: Parábola, 2002.

DIDI-HUBERMAN, Georges. Quando as imagens tocam o real. PÓS: Revista do Programa de Pós-graduação em Artes da EBA/ UFMG, Belo Horizonte, MG, v. 2, n. 4, p. 204-219, nov. 2012.

DUBOIS, Philippe. O ato fotográfico e outros ensaios. Tradução de Marina Appenzeller. Campinas, SP: Papirus, 1993.

FRANÇA, Vera Veiga. Paradigmas da comunicação: conhecer o quê? C-Legenda-Revista do Programa de Pós-graduação em Cinema e Audiovisual, Niterói, RJ, n. 5, 2001. https://periodicos. uff.br/ciberlegenda/article/view/36784. Acesso em: 7 jul. 2017.

\section{FUNDAÇÃO CULTURAL PALMARES. Comunidades}

remanescentes de quilombos (CRQ's). Brasília, DF: Fundação Cultural Palmares, 2016. Disponível em: http://www.palmares.gov. br/comunidades-remanescentes-de-quilombos-crqs. Acesso em: 7 jul. 2017.

KOSSOY, Boris. Fotografia e história. 4. ed. São Paulo: Ateliê Editorial, 2012.

KOSSOY, Boris. Realidades e ficções na trama fotográfica. São Paulo: Ateliê Editorial, 2009.

MARTINS, José de Souza. A fotografia e a vida cotidiana: ocultações e revelações. In: MARTINS, José de Souza. Sociologia da fotografia e da imagem. São Paulo: Contexto, 2008. v. 2, p. 33-62.

MAUAD, Ana Maria. Através da imagem: fotografia e história, interfaces. Tempo, Rio de Janeiro, RJ, v. 1, n. 2, p. 73-98, 1996. 
MENDOZA-HARRELL, Thomaz William. Da pintura rupestre à fotografia. In: MENDOZA-HARRELL, Thomaz William. Curso básico de fotografia. Uberlândia, MG: Universidade Federal de Uberlândia, 2002. Cap. 1, p1-p13. Manual de Fotografia 2002. Disponível em: www.tharrell.prof.ufu.br/default2.htm. Acesso em: 13 out. 2018.

NOVAES, Sylvia Caiuby. A construção de imagens na pesquisa de campo. Iluminuras, Porto Alegre, RS, v. 13, n. 31, p. 11-29, jul. / dez. 2012.

PRODANOV, Cleber Cristiano; FREITAS, Ernani Cesar de. Metodologia do trabalho científico: métodos e técnicas da pesquisa e do trabalho acadêmico. 2. ed. Novo Hamburgo: Feevale, 2013. Recurso eletrônico.

SALVAGNI, Julice; SILVEIRA, Marco Antônio Negri da.

Discursos imagéticos: a fotografia como método da pesquisa social. In: ENCONTRO GT DE HISTÓRIA, IMAGEM E CULTURA VISUAL, 2., 2013, Porto Alegre, RS. Anais eletrônicos [...]. Porto Alegre: ANPUH-RS: Associação Nacional de História, 2013. Disponível em: dIhttps:/www.anpuh-rs.org.br/conteudo/view?ID_ CONTEUDO=1337. Acesso em: 6 jul. 2017.

SODRÉ, Muniz. A comunicação eletrônica é epistemóloga.

Parágrafo, São Paulo, SP, v. 1, n. 3, jan. /jun. 2015. Disponível em: http://revistaseletronicas. fiamfaam.br/index.php/ recicofi / article/view/289. Acesso em: 6 jul. 2017.

SODRÉ, Muniz. A televisão é uma forma de vida. Revista FAMECOS, Porto Alegre, RS, n. 16, 2001. versão eletrônica. Disponível em: http://revistaseletronicas. pucrs.br/ojs/ index.php/ revistafamecos/article/view/3135/2406. Acesso em: 6 jul. 2017.

SODRÉ, Muniz. Sobre a episteme comunicacional. Revista 
Matrizes, São Paulo, SP, n. 1, out. 2007. versão eletrônica. Disponível em: https://www.revistas.usp.br/matrizes/article/ viewFile/38174/40899. Acesso em: 6 jul. 2017. 